\title{
BMJ Open Defining clinical empathy: a grounded theory approach from the perspective of healthcare workers and patients in a multicultural setting
}

\author{
Laurence Tan (D) , , ,2,3,4,5 Mai Khanh Le, ${ }^{2}$ Chou Chuen Yu, ${ }^{2}$ Sok Ying Liaw, ${ }^{6}$ \\ Tanya Tierney, ${ }^{3}$ Yun Ying Ho, ${ }^{3}$ Evelyn Lim, ${ }^{7}$ Daphne Lim, ${ }^{7}$ Reuben Ng (D) , 8,9 \\ Colin Ngeow, ${ }^{10}$ James Low ${ }^{1,2,5}$
}

To cite: Tan L, Le MK,

Yu CC, et al. Defining clinical empathy: a grounded theory approach from the perspective of healthcare workers and patients in a multicultural setting. BMJ Open 2021;11:e045224. doi:10.1136/ bmjopen-2020-045224

- Prepublication history for this paper is available online. To view these files, please visit the journal online (http://dx.doi. org/10.1136/bmjopen-2020045224).

Received 25 September 2020 Accepted 25 August 2021
Check for updates

(C) Author(s) (or their employer(s)) 2021. Re-use permitted under CC BY-NC. No commercial re-use. See rights and permissions. Published by BMJ.

For numbered affiliations see end of article.

Correspondence to

Dr Laurence Tan;

tan.laurence.lc@ktph.com.sg

\section{ABSTRACT}

Objective To define clinical empathy from the perspective of healthcare workers and patients from a multicultural setting.

Design Grounded theory approach using focus group discussions.

Setting A health cluster in Singapore consisting of an acute hospital, a community hospital, ambulatory care teams, a medical school and a nursing school.

Participants 69 participants including doctors, nurses, medical students, nursing students, patients and allied health workers.

Main outcome measures A robust definition of clinical empathy.

Results The construct of clinical empathy is consistent across doctors, nurses, students, allied health and students. Medical empathy consists of an inner sense of empathy (imaginative, affective and cognitive), empathy behaviour (genuine concern and empathic communication) and a sense of connection (trust and rapport). This construct of clinical empathy is similar to definitions by neuroscientists but challenges a common definition of clinical empathy as a cognitive process with emotional detachment

Conclusions This paper has defined clinical empathy as 'a sense of connection between the healthcare worker and the patient as a result of perspective taking arising from imaginative, affective and cognitive processes, which are expressed through behaviours and good communication skills that convey genuine concern'. A clear and multidimensional definition of clinical empathy will improve future education and research efforts in the application and impact of clinical empathy.

\section{INTRODUCTION}

There is general agreement that empathy is important in medicine. ${ }^{12}$ Studies have shown that empathy can improve both the quality and experience of care for patients and healthcare professionals. ${ }^{2-4}$ Interestingly, there is currently no consensus on the definition and construct of empathy even though the need for a consensus was recognised since

\section{Strengths and limitations of this study}

- This is the first study to comprehensively review the opinions of doctors, nurses, medical and nursing students, allied health and patients on clinical empathy.

- The study was done in a multicultural setting and participants are of different gender, ethnicity, religious beliefs and work in different setting (acute hospital, community hospital, home care and schools).

- Grounded theory approach using 14 focus groups involving 69 participants was employed to developed a definition of clinical empathy.

- Theory derived is in concordance with current evidence and theories on empathy both in the medical and non-medical literature.

- The study results are limited by the use of a single modality of data collection (focus group), which may come with biases such as social desirability bias.

$1948 .^{5}$ Within the field of biomedicine, clinical empathy had been described by experts in a predominantly cognitive and behavioural manner. Yet, empathy is known to be a complex multidimensional concept, ${ }^{67}$ that is personally experienced by healthcare professionals and patients themselves. Gaining an understanding of clinical empathy from the views of culturally different healthcare professionals and patients will help construct a consensus definition of empathy in clinical medicine.

Empathy was first described in the social psychology domain in the 1950s as a 'capacity to think and feel oneself into the inner life of another person' ${ }^{8}$ Rogers, who pioneered person-centred therapy, defined empathy relationally as 'a very special way of being with another person'. 9 Throughout history, the concept of empathy has gradually evolved from a predominantly cognitive aspect ${ }^{10}$ to 
one that includes affective, imaginative, behavioural and relational dimensions. ${ }^{11} 12$

The term 'clinical empathy' was used to describe empathy in the clinical setting. ${ }^{13}$ One of the important tools for quantitative assessment of empathy is the Jefferson Scale of Empathy (JSE). The authors of JSE defined clinical empathy as 'a predominantly cognitive attribute' combined with 'a capacity to communicate this understanding'. ${ }^{14}$ They further argued that clinical empathy had to be contrasted with sympathy that was defined as 'feeling with the patient'. ${ }^{15}$ This notion of detached concern was traditionally accepted in medicine as it was believed that emotions threaten objectivity and that being detached is the best way to provide care to patients. ${ }^{16}$ The affective aspect of empathy has been suggested to blur professional boundaries ${ }^{17}$ and cause burnout in healthcare professionals. ${ }^{18}$ However, this cognitive construct of clinical empathy has been challenged by medical writers such as Halpern and Spiro who believed that clinical empathy cannot be purely affective or cognitive. Halpern defined empathy as the ability to feel the patient's experience ${ }^{19}$ while Spiro wrote 'For me, empathy arises out of our own feelings and reactions; it happens when 'you and I' becomes 'I am you". ${ }^{20}$ Maxwell suggested that polarising empathy between cognition and emotion is unhelpful and both aspects of empathy are important. ${ }^{21}$

The lack of consensus to the definition and construct of clinical empathy may be the result of two factors. First, clinical empathy was traditionally defined in the literature by medical experts, rather than by healthcare professionals and patients themselves. Second, while empathy is known to be a multidimensional concept that is affected by culture ${ }^{22}$ most empiric studies on empathy within biomedicine have been limited to western countries, especially the USA and UK.

Culture is defined as 'an integrated pattern of learnt beliefs and behaviours' and includes 'thoughts, communication styles, ways of interacting, views of roles and relationships, values practices and customs' ${ }^{23}$ Given that some elements of culture are interlinked with the dimensions of empathy such as cognition and behaviour, it is, therefore, imperative to consider cultural differences within the study of clinical empathy.

In Singapore, where this study was conducted, the context is unique in that while the population is influenced by the Confucianism ${ }^{24}$ and traditional Asian cultures, the education system is derived from both the British and American educational systems. An internist in Singapore could have taken both the membership examinations from the Royal Colleges of the UK and/or the American Board Exams from the USA. This amalgamation of cultures and educational systems serves as a rich and fertile ground from which medical empathy can be studied and understood.

There has been no study that comprehensively reviewed the opinions of doctors, nurses, medical and nursing students and patients collectively. Conducting such a study especially in a multicultural setting would allow clinical empathy to be defined more holistically. Having a holistic and accurate definition of empathy is important in order to study the positive and detrimental effect of empathy on patients and healthcare workers (HCWs) and the skills needed to balance the need for clinical empathy and professional boundaries. This study aims to define clinical empathy from the perspectives of different groups of healthcare professionals who included doctors, nurses, medical students, nursing students, allied health professionals and patients in a multi-cultural setting.

\section{METHODS}

The study employed a grounded theory approach where data were collected and analysed simultaneously. Data were collected through focus group discussions (FGDs) with HCWs and healthcare recipients (patients) to ensure different perspectives around empathy are gathered.

Email invitation was sent to potential participants in a health cluster in Singapore consisting of an acute hospital, a community hospital, ambulatory care teams, a medical school and a nursing school. Participants attended the FGD once. The FGDs were held at participants' place of work or study to make it convenient for them to participate.

The FGDs were conducted in rotating pairs by three investigators. LT is a male doctor, MK is a female researcher and CC is a male researcher. MK and CC had educational qualifications in psychology. All three investigators were familiar with the conduct of FGDs through previous studies. The interview guide for the first FGD was developed from existing theories of empathy. The discussions focused on the definition and construct of clinical empathy. Negative case discussions (what is the opposite of empathy?) were intentionally introduced to improve the validity of the data. ${ }^{25}$ After each FGD, the researchers met to analyse the data based on session notes and audio recordings, and they revised the question guide according to the new themes that arose from the preceding session in preparation for the next FGD. The investigators explained the research's purpose at the beginning of the FGD and informed consent was taken from all participants.

A total of 14 FGDs involving 69 participants consisting of homogenous groups of medical students (clinical years), nursing students (clinical years), doctors, nurses, allied HCWs and patients were conducted (table 1). The FGDs were carried out with homogenous groups in order to avoid potential biases caused by imbalance in power dynamics (eg, students and working professionals, care providers and care recipients) and to encourage participants to freely share their ideas. Purposively sampling was done in order to select HCWs who were diverse in demographics, clinical specialities and clinical experiences. Ten of the FGD sessions were used to create the construct for empathy. Two FDGs consisting of senior specialty nurses and members of the palliative multidisciplinary 


\begin{tabular}{|c|c|c|c|c|c|c|}
\hline $\begin{array}{l}\text { FGD } \\
\text { number }\end{array}$ & Group & $\mathbf{N}$ & Gender & Age & Race & $\begin{array}{l}\text { Duration } \\
\text { (hour:min:s) }\end{array}$ \\
\hline 1 & Nurse & 6 & Female $(n=6)$ & $\begin{array}{l}M=31.83 \\
S D=10.91\end{array}$ & $\begin{array}{l}\text { Chinese }(n=2) \\
\text { Others }(n=4)\end{array}$ & 1:07:15 \\
\hline 2 & Medical student & 6 & $\begin{array}{l}\text { Male }(n=4) \\
\text { Female }(n=2)\end{array}$ & $\begin{array}{l}M=22.83 \\
S D=0.98\end{array}$ & Chinese $(n=6)$ & $1: 24: 00$ \\
\hline 3 & Medical student & 5 & $\begin{array}{l}\text { Male }(n=4) \\
\text { Female }(n=1)\end{array}$ & $\begin{array}{l}M=22.60 \\
S D=0.89\end{array}$ & $\begin{array}{l}\text { Chinese }(n=4) \\
\text { Indian }(n=1)\end{array}$ & 1:15:00 \\
\hline 4 & Medical student & 6 & $\begin{array}{l}\text { Male }(n=5) \\
\text { Female }(n=1)\end{array}$ & $\begin{array}{l}M=22.33 \\
S D=0.52\end{array}$ & $\begin{array}{l}\text { Chinese }(n=4) \\
\text { Malay }(n=1) \\
\text { Indian }(n=1)\end{array}$ & 1:16:35 \\
\hline 5 & Medical student & 4 & $\begin{array}{l}\text { Male }(n=1) \\
\text { Female }(n=3)\end{array}$ & $\begin{array}{l}M=22 \\
S D=0.00\end{array}$ & Chinese $(n=4)$ & $1: 29: 13$ \\
\hline 6 & Physician & 5 & Female $(n=5)$ & $\begin{array}{l}M=32.60 \\
S D=3.91\end{array}$ & $\begin{array}{l}\text { Chinese }(n=4) \\
\text { Others }(n=1)\end{array}$ & $1: 26: 41$ \\
\hline 7 & Nurse & 5 & $\begin{array}{l}\text { Male }(n=1) \\
\text { Female }(n=4)\end{array}$ & $\begin{array}{l}M=41 \\
S D=15.41\end{array}$ & $\begin{array}{l}\text { Chinese }(n=3) \\
\text { Malay }(n=1) \\
\text { Indian }(n=1)\end{array}$ & $1: 27: 59$ \\
\hline 8 & Patient & 4 & $\begin{array}{l}\text { Male }(n=3) \\
\text { Female }(n=1)\end{array}$ & $\begin{array}{l}M=59.50 \\
S D=16.98\end{array}$ & $\begin{array}{l}\text { Chinese }(n=2) \\
\text { Malay }(n=2)\end{array}$ & $1: 27: 02$ \\
\hline 9 & Nursing student & 5 & Female $(n=5)$ & $\begin{array}{l}M=28.80 \\
S D=9.34\end{array}$ & $\begin{array}{l}\text { Chinese }(n=1) \\
\text { Malay }(n=2) \\
\text { Indian }(n=1) \\
\text { Others }(n=1)\end{array}$ & 1:29:07 \\
\hline 10 & Nursing student & 4 & $\begin{array}{l}\text { Male }(n=1) \\
\text { Female }(n=3)\end{array}$ & $\begin{array}{l}M=23.50 \\
S D=5.07\end{array}$ & $\begin{array}{l}\text { Chinese }(n=1) \\
\text { Malay }(n=2) \\
\text { Indian }(n=1)\end{array}$ & 1:27:09 \\
\hline 11 & Multidisciplinary team & 5 & $\begin{array}{l}\text { Male }(n=2) \\
\text { Female }(n=3)\end{array}$ & $\begin{array}{l}M=33.40 \\
S D=7.89\end{array}$ & $\begin{array}{l}\text { Chinese }(n=4) \\
\text { Malay }(n=1)\end{array}$ & 1:13:54 \\
\hline 12 & Nursing student & 4 & $\begin{array}{l}\text { Male }(n=2) \\
\text { Female }(n=2)\end{array}$ & $\begin{array}{l}M=22.75 \\
S D=0.96\end{array}$ & Chinese $(n=4)$ & $1: 31: 20$ \\
\hline 13 & Nursing student & 5 & Female $(n=5)$ & $\begin{array}{l}M=29.4 \\
S D=9.40\end{array}$ & $\begin{array}{l}\text { Chinese }(n=2) \\
\text { Malay }(n=2) \\
\text { Others }(n=1)\end{array}$ & $1: 31: 18$ \\
\hline 14 & Patient & 5 & $\begin{array}{l}\text { Male }(n=2) \\
\text { Female }(n=3)\end{array}$ & $\begin{array}{l}\text { (Undisclosed } \\
\mathrm{n}=1 \text { ) } \\
\mathrm{M}=61.5 \\
\mathrm{SD}=15.67\end{array}$ & $\begin{array}{l}\text { Chinese }(n=4) \\
\text { Indian }(n=1)\end{array}$ & $1: 15: 54$ \\
\hline
\end{tabular}

team were selected specifically to verify the construct of empathy from the 'user' end of empathy, as they were deemed to 'use and dispense' a high level of empathy in their practice. ${ }^{26}$ Two FDGs consisting of patients were specially conducted near the middle (8th FDG) and at the end (14th FDG) of the study in order to provide a reciprocal point of view on clinical empathy as receivers of empathy.
On completion of every two FGDs, the audio recordings were transcribed ad verbatim by one of two investigators (YY and MKL) and counterchecked against the recordings by LT. The three investigators who conducted the interviews then coded and thematically analysed the transcripts independently according to the framework described by Guest. ${ }^{27}$ The investigators subsequently met monthly over a year to compare codes to form themes and 
any difference in opinion was mediated till a consensus was reached. A coherent theory revolving around the construct of clinical empathy was drafted by the third FGD. The construct was further refined throughout the study until data saturation and a stable construct was reached by the 14th FGD.

An attempt was made to ensure that the accepted themes were expressed consistently in every group of participants, rather than being confined to only certain groups. The theoretical model developed was triangulated $^{28}$ to pre-existing models found in the medical literature.

The interview guide can be obtained from the authors on request.

\section{Patient and public involvement}

Patients and the public were not involved in the design and planning of this study. However, participants' inputs during the focus group shape the discussion for the later groups as part of grounded theory methodology.

\section{RESULTS}

Across the groups of HCWs, the construct of empathy was consistent and in concordance with the patient groups. Clinical empathy was viewed as a sense of connection, which was the result of an intrinsic sense of empathy juxtaposed with empathic behaviours. The intrinsic sense of empathy consisted of four components while empathic behaviour consisted of two domains. All groups emphasised that empathy must be genuine ('comes from the heart') and that attempts to 'fake' empathy would be easily detected and have a counteractive effect on rapport. The domains of empathy elicited in the study were compared with the past literature in table 2. Overall, our results show that HCWs viewed empathy as a multidomain, relational trait.

Some differences in opinions were elicited between groups. Nurses tended to believe that clinical empathy was an integral part of the profession, while doctors tended to believe that empathy was a good attribute to have on top of clinical competence. All groups, including the patients, were able to share scenarios where empathy was clinically inappropriate (eg, during surgery and in emergency situations).

\section{Construct of clinical empathy}

1. Intrinsic sense of empathy

Participants described three components that created an intrinsic sense of empathy. These components described the psychoemotional processes in which a healthcare professional encountered empathy internally (without expressing the empathy). The three components were putting myself in patients' shoes, feeling what patients are feeling and understanding the perspective of patients.

a. Putting yourself in the shoes of others (imaginative component)

...empathy is putting yourself in other's shoes - just like that-

nurse, FGD 1.

Empathy was strongly and repeatedly described as an imaginative process. The most common phrase used was 'putting myself in their shoes'. This came out in all 14 FGDs and was

Table 2 Definitions of empathy: past and present

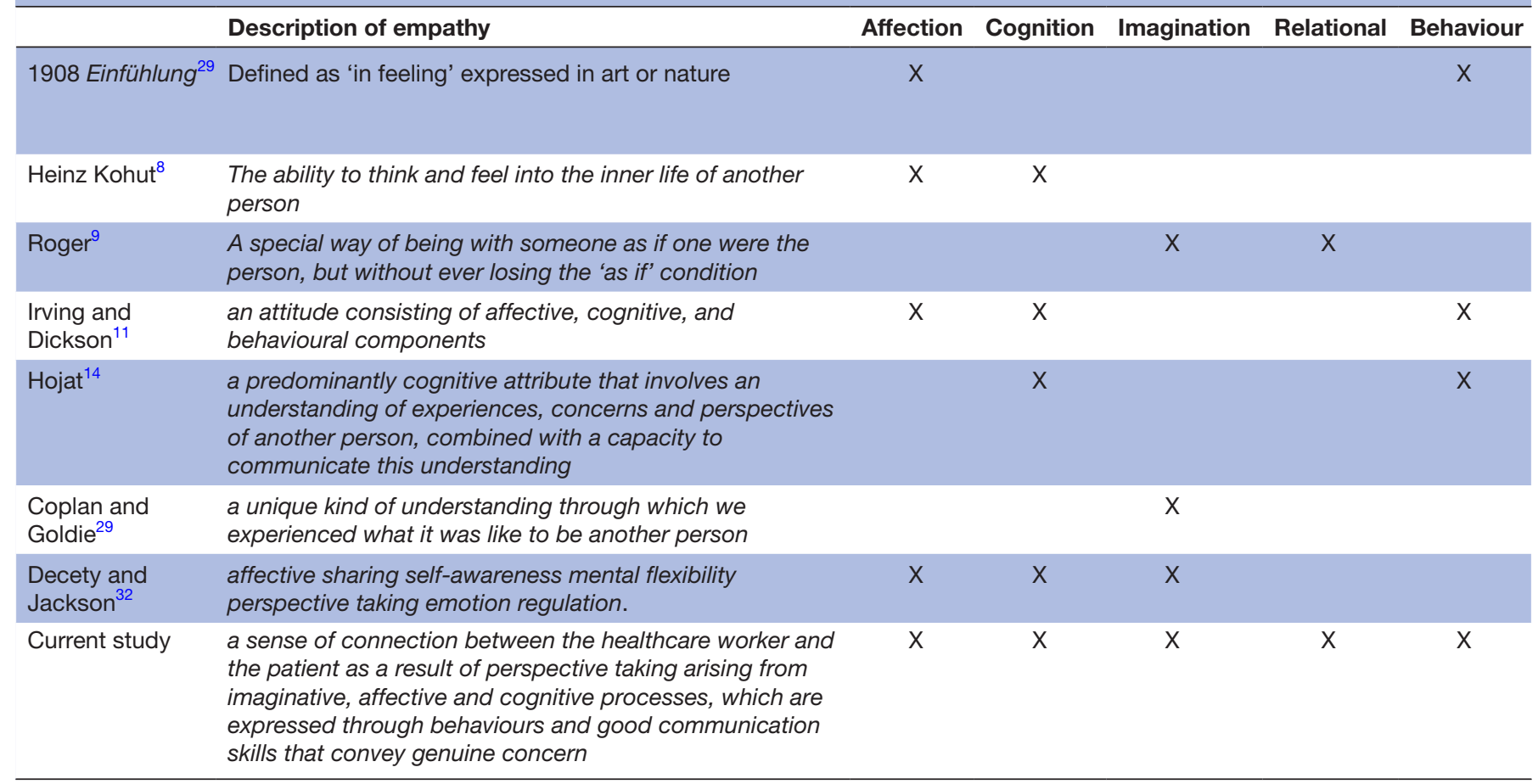


repeated by most participants within each FGD. Participants described empathy both as a process of imagining how they would feel if they were a patient, which was a self-orientated response or imagining how the patient would feel in their current situation, which is an other-orientated response. ${ }^{29}$ Participants did not elaborate if a self-orientated or otherorientated response was better, but they agreed that imagination was needed for empathy.

As-as for-for me right, I think empathy has got a lot to do with imagination, because when you see the person experience a certain situation, you try to imagine what is it like by dipping into your own personal life and experience, to appreciate and to understand from the person's point of view-

multidisciplinary team member, FGD 11.

Some participants distinguished the imaginative process as separate from the affective and cognitive components, while others believed that imagination preceded the emotions and thoughts associated with empathy. A third group saw all three components as possibly occurring concurrently and in no particular order.

b. Feeling what others are feeling (affective component)

Most participants viewed emotional resonance as 'normal' and 'important' in clinical empathy. 'It is about feeling what the patient feels' was a common description of clinical empathy. Participants believed that by doing so, it would allow HCWs to adapt and individualise their communication and clinical care, taking into account the emotional states of patients. Specifically, many participants spoke about empathy as a concordance in feeling (feeling with) rather than imposing one's own emotions (feeling for) on someone.

...it's about feeling with someone, rather than feeling for someone-

speciality nurse, FGD 7.

Participants were aware that too much emotions might cloud clinical judgement and cause emotional distress in the HCW. Although most participants suggested that their professional training had taught them how to draw clear boundaries between their personal and professional lives, they did struggle in trying to balance the need for emotional resonance and maintaining professional comportment. ${ }^{30}$ Participants generally agreed that there were situations, for example, in emergency or surgical care, where a level of high level of detachment is required for clinicians to bring to bear their full professional skills.

I think it's very hard to draw a line as to how (to keep a boundary)- I think it's a spectrum right, from just feeling empathy to investing too much feelings. Um, ideally there should be like a fine balance but realistically I think it's very hard-

medical student, FGD 2.

c. Understanding what others are going through (cognitive component)
While there was a strong emphasis on imaginative and affective aspects of empathy, participants specifically brought up the concomitant need to cognitively understand the patient's perspectives. Participants expressed that the imaginative and affective processes are often clouded by personal experiences and bias. An intentional cognitive exercise to understand the perspective and emotions of the patient is important in allowing HCWs to fully understand the patient.

For me maybe you don't jump into conclusion, you find the root cause first. You know them in-depth first rather than you just jump to conclusions why they react this way, so to understand them more-

nurse, FGD 10.

While HCWs may instinctively feel certain emotions, there is a purposeful sense of cognitive awareness of these emotions, and how they impact the HCW, the patient and the HCW-patient relationship. This is thought to reduce the effect of biasness resulting from self-orientated empathy (how would I feel if I was the patient) and acts as a buffer to protect boundaries in the HCW-patient relationship from being compromised.

...empathy is more than a feeling. It's like what the rest said, it's about understanding from the patient's point of view...-

medical student, FGD 2.

\section{Empathic behaviour}

Participants agreed that an intrinsic sense of empathy did not necessarily result in empathic behaviours. For clinical empathy to be fully actualised, the intrinsic sense of empathy must be accompanied by empathic behaviours. These empathic behaviours can be summarised into two domains, showing genuine concern and communicating empathy to a fellow human being. Participants were often unable to clearly demarcate the differences between the two domains, suggesting that there are some overlaps in the conceptual understanding of these two domains.

a. Showing genuine concern

'Empathy is about people, not about tasks' - this was the overarching theme throughout the FGDs. Tasks require skills and time, while people require attention and care. Participants felt that showing patients that HCWs were truly concerned about the latter's well-being was a good way to demonstrate empathy. This involved looking into the little details about the patients' well-being ('has she eaten', 'is she cold') to showing concern about the social lives of patients ('what is happening at home', 'are there any financial concerns'). Some participants considered this to be patient-centred care, ${ }^{31}$ which entails caring for patients beyond mere disease treatment, to include looking at the patient as a whole person made up of differing, yet unique social, psychological and spiritual dimensions.

...like do I know the patient's name? Do I remember what he looks like? Uh, do I know how many family 
members he has? And then I remind myself that actually I don't know then perhaps I haven't been showing enough empathy...-

doctor, FGD 6.

The antithesis of empathy was being task oriented. This means putting the need to complete tasks above the need to show concern to patients. The ability to complete tasks efficiently and effectively has been the cornerstone of medical and nursing training. Even participants who saw themselves as the most empathic described moments where they took on a task-oriented approach to care, only to remind themselves that they were there to serve patients and not merely perform a task. Despite the competing need to complete tasks and to show care, most participants agreed that displaying empathy did not require much time and effort. In fact, a simple gesture to show genuine care and concern required less effort than to put on several non-genuine task-oriented gestures of care.

...this doctor continued on with the consult in a very robotic manner, and I really felt that he was just, you know- he just wanted to get his work over and done with and get out of clinic for that day...-

$$
\text { medical student, FGD } 5 .
$$

Participants believed that patients were able to discern if a HCW was truly genuine in providing empathic care to them or if they were masquerading their actions as empathy. Insincere or false empathy not only disrupted the HCW-patient relationship but had a detrimental psychological effect on HCWs as well.

So you have to be a very very good actor to carry on faking. If you're not genuine the patient can tell. If you fake it, you don't feel good yourself-

doctor, FGD 6.

\section{b. Communicating empathy}

Communication skills were considered to be an integral part of conveying empathy. Both HCW and patient participants agreed that an intrinsic sense of empathy is clinically useful insofar as it is translated into actions that are communicated to the patient by way of words and deeds. Communicating empathy was described as the sharing and exchange of perspectives, feelings and reflections of both the patient and the HCW. It paves the way for the provision of compassionate care to patients and their families.

Particular emphasis was placed on non-verbal communications and the role of active listening by participants. While verbal skills like paraphrasing a patient's words were deemed to be useful, it was felt that non-verbal cues played a more important role in communicating empathy.

...body language and the tone of your voice- the tone that you speak in is also very important, eye contact as well, all these things are quite important to like show your empathy- medical student, FGD 5 .

Active listening was said to be even more important than verbal and non-verbal communication skills. Active listening was described as the ability to understand the patient and make the patient feel heard and understood. It conveys a sense of presence to the patient. Good communication skills can be honed with practice but must be genuine to the effective communicator. Patients were able to quote examples of doctors who paraphrased the words of the patients as a learnt and rehearsed communication skill rather than genuine active listening.

...if you really want to show the empathy, I agree with the sister who said that you have to listen. They have to listen. They have to listen to the patient and then from there they can advise if what they say is reasonable or good for them (patients). But first things first, they have to listen-

patient, FGD 8.

3. Empathy as a sense of trust and bonding (connection) Participants saw empathy as enabling a sense of connection between the patients and HCW. This observation was more obvious among nurses and nursing students compared with doctors and medical students. The two 'practitioners of high levels of empathy' groups consisting of specialist nurses and the multidisciplinary palliative team felt that this was a very important aspect of empathy. When explored further, participants could not tell the difference between the sense of connectedness and clinical empathy itself, meaning that these two concepts were almost synonymous to the participants.

...if I don't identify with the feeling cognitively first of all, then I don't identify with the feeling emotionally right. It's very hard for me to put in words for them that I see their point of view and that I try to feel what they're going through. To me this is about a very powerful connection. I work with many of my patients and their caregivers. Without an emotional connection, it's almost impossible for them to know that I truly am walking with them. It's a connection, it's very hard to explain what it is-

$$
\text { multidisciplinary team, FGD } 11 .
$$

...people who feel more bonded, or feel that you give them a reason to trust you, or feel comfortable between you and them, or feel that you step yourself in their shoes will feel more bonded to you-

$$
\text { nursing student, FGD } 12 .
$$

Participants articulated that a sense of connection was fostered when the HCW, who experienced an intrinsic sense of empathy for the patient and communicated this to the latter, fostered reciprocal trust, rapport and bonding, which then resulted in forging a holistic 'therapeutic alliance'.

4. Cultural aspects of clinical empathy 
Despite cultural differences between the participants, the construct of empathy was consistently similar. Participants also expressed that empathy is important to patients regardless of culture, because genuine care and a sense of being understood is universally important. Despite a recurrent theme emplacing on the need to personalise empathy using person-centred approach, the use of the word culture, race, gender and ethnicity was rare. While there were some discussions of the role of spiritual beliefs and religion on empathy, there was insufficient data for this subtheme to saturate.

When culture was mentioned in the FGDs, participants described how personal values and cultural norms of healthcare professionals and their patients can affect the expression and interpretation of empathic behaviours. Participants who mentioned culture agreed that cultural barriers to empathy can be resolved by a genuine resolve to care for the patients. Discussion on spiritual beliefs or religion was mainly centred around its role in shaping the development and valuation of empathy for both HCWs and patients.

...the way they talk to you, I think to them is very polite already, but it is actually rude to us-

patient, FDG 14.

\section{DISCUSSION}

Clinical empathy is highly complex because it is perceived, understood and expressed in a multidomain, multidimensional and relational manner by HCWs and patients. This organic and dynamic process incorporates more than just the cognitive or affective dimensions of what it means to be human. In essence, it is a fluid state of disposition that attempts to connect the HCW and patient through an interactive engagement or communication that draws on the cognitive, affective and imaginative aspects of empathy. It sets the tone for a caring or compassionate relationship between the caregiver and patient. Only when there is human connection through empathy can genuine care be provided and emphatic behaviour manifests itself.

Our results showed that HCWs and patients consistently described empathy as a process comprising of cognitive, affective and imaginative aspects. In addition, this sense of empathy needs to be communicated to patients resulting in a sense of trust and connection. This construct of empathy is in line with sociocognitive neuroscience studies. Decety and Jackson ${ }^{32}$ combined both neuroscience and social science data to describe empathy as a combination of four components, namely, affective sharing (sharing the same emotions), self-awareness (being able to differentiate self from others), mental flexibility and perspective taking (to learn and imagine another person's perspective) and emotion regulation (to regulate one's own emotions that can interfere with work). They believed that all four components must be activated in the neural network for empathy to occur. Our findings concur with their model of empathy, which underscored the importance of affective (affective sharing), imaginative (perspective taking) and cognitive (self-awareness and emotion regulation) components in clinical empathy.

Mercer believed that in order for empathy to be meaningful, it must be communicated and acted on a helpful way. ${ }^{17}$ Our study participants concurred with this and believed that empathy should bring to fruition its expression in the behavioural domain. This entails both verbal and non-verbal communications ${ }^{31} 33$ and adopting a person-centred approach to providing care that extends beyond the physical to the psychosocial domains of a patient. ${ }^{34}$ In addition to verbal and non-verbal communication skills, as an integral part of empathy, ${ }^{15}$ our results also spoke of the central role of active listening. Active listening conveyed the 'presence' of the HCW to the patient in mind, body and affect. Therefore, training in active listening could go a long way in improving clinical empathy, ${ }^{35} 36$ especially in HCWs who already possess the inner qualities of empathy (imaginative, affective and cognitive) but lack the ability to communicate this inner empathy well.

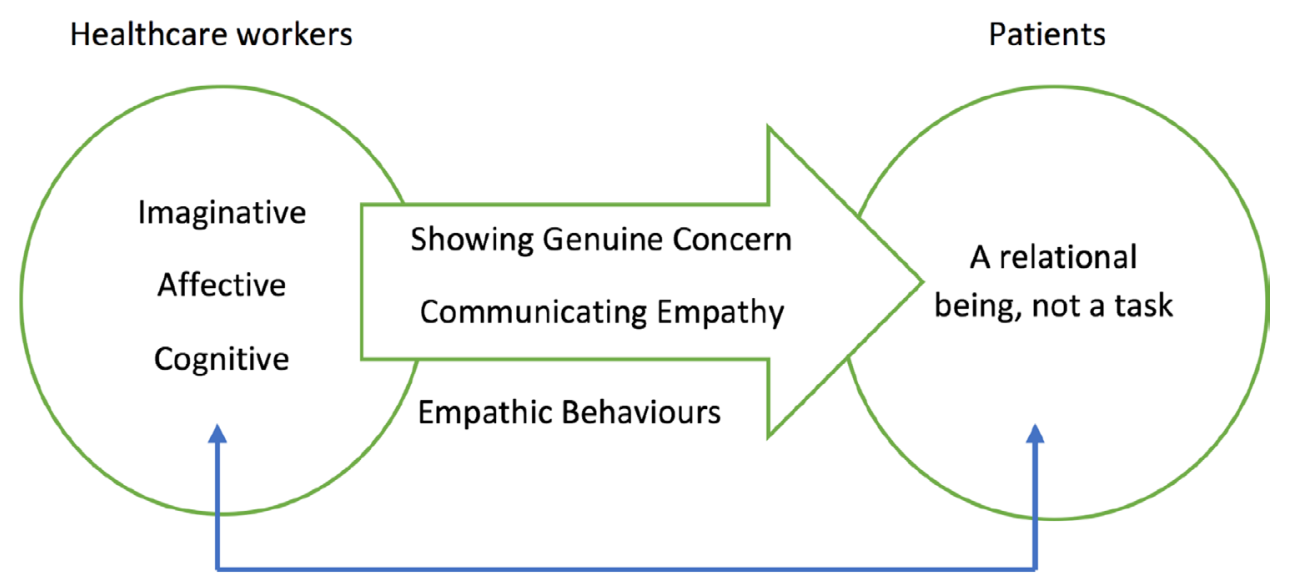

Sense of Connection

Figure 1 Construct of clinical empathy. 
Clinical empathy from the expert point of view has been traditionally viewed as a predominantly cognitive process, rationalised by the need to provide objective clinical care to patients. ${ }^{37}$ However, our study found that both HCWs and patients described empathy in a multidimensional manner rather than as a predominantly cognitive exercise. We observed that when healthcare professionals have the intrinsic sense of empathy (imaginative, affective and cognitive), which is communicated using empathic behaviours (showing genuine concern and communicating empathy), the result is a sense of connection, bonding and trust, which is synonymous with clinical empathy. This observation is explained in a conceptual model, showing the interdependant relationships of the various components of clinical empathy (figure 1). The model illustrates that the empathic behaviour is a relational one that attempts to build connection, trust and bonding. This relational view of clinical empathy is consistent with the view of some medical scholars who saw clinical empathy as a sense of connection or bonding. ${ }^{38} 39$ This is further supported by social scientists' view of social empathy as being a sense of shared connection. ${ }^{40} 41$

A fascinating result from this multioccupation, multicultural grounded study was that the participants did not view the construct of empathy differently across occupation, culture, job seniority and from the western literature. The results, however, showed that differences in occupation, specialisation and job seniority affect the level of appreciation for the importance of empathy in clinical work. Cultural differences have been suggested to affect empathic behaviour. ${ }^{42}$ Our study showed that HCWs were aware of the need to overcome cultural differences by personalising care and building relationships with patients using a person-centred approach. This is similar to the concept of cultural competent, ${ }^{43}$ which is defined as the ability to understand, appreciate and interact with people from cultures or belief systems different from one's own. ${ }^{44}$ The cultural aspect is an important component of empathy although it did not saturate as a theme by the end of the study.

Amalgamating the result of this study and current literature, we wish to propose the definition of clinical empathy as 'a sense of connection between the HCW and the patient as a result of perspective taking arising from imaginative, affective and cognitive processes, which are expressed through behaviours and good communication skills that convey genuine concern'.

The strength of the study lies having enough participants from various occupations, seniority and culture in order to reach a stable construct of clinical empathy. The results were further verified by having patient groups and groups of highly empathic HCWs and triangulated with the current literature. While participants came from diverse cultural backgrounds in Singapore, their views echo the views of scholars on empathy in the literature, suggesting that the proposed definition of clinical empathy is applicable in the international community. The key limitation to the study was that the approach of the study focused on discovering common construct of empathy across groups, thereby neglecting to learn and expound on the differences between the groups. Given the multicultural setting of the study, this would have resulted in possibly rich data being unexplored. An additional limitation of the study is that the use of FGDs may induce social desirability bias ${ }^{45}$ in the participants, resulting in data that may be socially desirable rather than truly reflective of the participants' personal views.

Clinical empathy is important for good and effective patient care. Any attempts at training HCWs in empathy must take into account the complex interactions between the different components of empathy, focusing on the ability to form a sense of connection. This would ensure that a complex relational attribute is not reduced to being a mere thinking or behavioural construct.

\section{CONCLUSION}

This ground up study of clinical empathy from the perspective of HCWs and patients in a multicultural setting hopes to provide a consensus that clinical empathy is multidimensional and comprises of cognitive, affective, imaginative and behavioural components, resulting in a relational sense of trust and bonding. This clearer, cogent and more inclusive definition of clinical empathy would allow future education and research efforts to improve on the understanding of the cofounding factors of clinical empathy and its impact. Cultural and occupational differences clearly affect empathy, and future research into these aspects of clinical empathy is important to allow clinical empathy to be effectively used.

\section{Author affiliations}

${ }^{1}$ Department of Geriatic Medicine, Khoo Teck Puat Hospital, Singapore

${ }^{2}$ Geriatric Education and Research Institute Ltd, Singapore

${ }^{3}$ Lee Kong Chian School of Medicine, Singapore

${ }^{4}$ The Palliative Care Centre for Excellence in Research and Education, Singapore

${ }^{5}$ Gericare, Khoo Teck Puat Hospital, Singapore

${ }^{6}$ Alice Lee Centre for Nursing Studies, Singapore

${ }^{7}$ School of Health \& Social Sciences, Nanyang Polytechnic, Singapore

${ }^{8}$ Lee Kuan Yew School of Public Policy, National University of Singapore, Singapore

${ }^{9}$ Lloyds Register Foundation Institute for the Public Understanding of Risk, National

University of Singapore, Singapore

${ }^{10}$ Tan Tock Seng Hospital, Singapore

Acknowledgements We acknowledge Dr Jennie Wong of Medical and Scientific Communication, Research Support Unit, National University Health System, Ms Lim Yujun and Mr Perry Lee of Gericare, Khoo Teck Puat hospital for editing and formating this manuscript.

Contributors LT is the principal investigator of the study who made significant contribution to study design, investigation, analysis and writing of this manuscript. MKL made significant contribution to study design, investigation, analysis, study administration and reviewing this manuscript. CCY made significant contribution to study design, investigation, analysis, and reviewing this manuscript. SYL, EL, $\mathrm{DL}, \mathrm{CN}$ made major contribution to investigation and reviewing this manuscript. TT made major contribution to study design, investigation, and reviewing of this manuscript. YYH made major contribution to study investigation and reviewing of this manuscript. RN made major contribution to study design and reviewing of this manuscript. JL made major contribution to study design, investigation and reviewing of this manuscript.

Funding This work was supported by Geriatric Education \& Research Institute's intramural fund (reference number GERI1616). All authors had full access to all 
of the data (including statistical reports and tables) in the study and can take responsibility for the integrity of the data and the accuracy of the data analysis.

Competing interests None declared.

Patient and public involvement Patients and/or the public were not involved in the design, or conduct, or reporting, or dissemination plans of this research.

Patient consent for publication Not required.

Ethics approval This study was approved by the National Healthcare Group Domain Specific Review Board (DSRB reference number 2018/00020) and Nanyang Polytechnic Institutional Review Board (NYP IRB reference number SHS-2018-004).

Provenance and peer review Not commissioned; externally peer reviewed.

Data availability statement No data are available.

Open access This is an open access article distributed in accordance with the Creative Commons Attribution Non Commercial (CC BY-NC 4.0) license, which permits others to distribute, remix, adapt, build upon this work non-commercially, and license their derivative works on different terms, provided the original work is properly cited, appropriate credit is given, any changes made indicated, and the use is non-commercial. See: http://creativecommons.org/licenses/by-nc/4.0/.

\section{ORCID iDs}

Laurence Tan http://orcid.org/0000-0001-8835-7175

Reuben Ng http://orcid.org/0000-0002-1186-0570

\section{REFERENCES}

1 Decety J, Fotopoulou A, Aikaterini F. Why empathy has a beneficial impact on others in medicine: unifying theories. Front Behav Neurosci 2014;8:457.

2 Bellet PS, Maloney MJ. The importance of empathy as an interviewing skill in medicine. JAMA 1991;266:1831-2.

3 Hojat M, Gonnella JS, Mangione S, et al. Physician empathy in medical education and practice: experience with the jefferson scale of physician empathy. Seminars in Integrative Medicine 2003;1:25-41.

4 Hemmerdinger JM, Stoddart SDR, Lilford RJ. A systematic review of tests of empathy in medicine. BMC Med Educ 2007;7:24.

5 Reik T. Listening with the third ear. New York: Farrar, Straus \& Co, 1983.

6 Davis $\mathrm{MH}$. Measuring individual differences in empathy: evidence for a multidimensional approach. J Pers Soc Psychol 1983;44:113-26.

7 Dvash J, Shamay-Tsoory SG. Theory of mind and empathy as multidimensional constructs: neurological foundations. Topics in Language Disorders 2014;34:282-95.

$8 \mathrm{KOHUT} \mathrm{H}$, Introspection KH. Introspection, empathy, and psychoanalysis; an examination of the relationship between mode of observation and theory. J Am Psychoanal Assoc 1959;7:459-83.

9 Rogers CR. Empathic: an unappreciated way of being. Couns Psychol 1975:5:2-10.

10 Epstein RM, Street RL. The values and value of patient-centered care. Ann Fam Med 2011;9:100-3.

11 Irving P, Dickson D. Empathy: towards a conceptual framework for health professionals. Int J Health Care Qual Assur Inc Leadersh Health Serv 2004;17:212-20.

12 Batson CD. The altruism question: toward a Social-Psychological answer. Hillsdale, MI, USA: Erlbaum, 1991.

13 Berger DM. Clinical empathy. Jason Aronson, 1987.

14 Hojat M. Ten approaches for enhancing empathy in health and human services cultures. J Health Hum Serv Adm 2009;31:412-50.

15 Hojat M. Empathy in health professions education and patient care. Switzerland: Springer International Publishing, 2016.

16 Halpern J. From detached concern to empathy: humanizing medical practice. Oxford University Press, 2001.

17 Mercer SW, Reynolds WJ. Empathy and quality of care. British Journal of General Practice 2002;52:S9-12.
18 Williams CA. Empathy and burnout in male and female helping professionals. Res Nurs Health 1989;12:169-78.

19 Halpern J. What is clinical empathy? J Gen Intern Med 2003;18:670-4.

20 Spiro H. Commentary: the practice of empathy. Acad Med 2009;84:1177-9.

21 Maxwell B. Professional ethics education: studies in compassionate empathy. Springer Science \& Business Media, 2008.

22 Chung W, Chan S, Cassels TG. The role of culture in affective empathy: cultural and bicultural differences. J Cogn Cult 2010;10:309-26.

23 Betancourt JR. Cross-cultural medical education: conceptual approaches and frameworks for evaluation. Acad Med 2003;78:560-9.

24 Tan C. "Our shared values" in Singapore: a confucian perspective. Educ Theory 2012;62:449-63.

25 Gliner JA. Reviewing qualitative research: proposed criteria for fairness and rigor. The Occupational Therapy Journal of Research 1994;14:78-92

26 Claxton-Oldfield S, Banzen Y. Personality characteristics of hospice palliative care volunteers: the "big five" and empathy. Am J Hosp Palliat Care 2010;27:407-12.

27 Guest G, MacQueen KM, Namey EE. Applied thematic analysis. SAGE publications, 2011.

28 Carter N, Bryant-Lukosius D, DiCenso A, et al. The use of triangulation in qualitative research. Oncol Nurs Forum 2014;41:545-7.

29 Coplan A, Goldie P. Empathy: philosophical and psychological perspectives. Oxford University Press, 2011.

30 Clickner DA, Shirey MR. Professional comportment: the missing element in nursing practice. Nurs Forum 2013;48:106-13.

31 Riess H, Kelley JM, Bailey RW, et al. Empathy training for resident physicians: a randomized controlled trial of a neuroscience-informed curriculum. J Gen Intern Med 2012;27:1280-6.

32 Decety J, Jackson PL. A social-neuroscience perspective on empathy. Curr Dir Psychol Sci 2006;15:54-8.

33 Kramer D, Ber R, Moore M. Increasing empathy among medical students. Med Educ 1989;23:168-73.

34 Sarafino EP, Timothy WS. Health psychology: biopsychosocial interactions. John Wiley \& Sons, 2014.

35 Miller WR, Hedrick KE, Orlofsky DR. The helpful responses questionnaire: a procedure for measuring therapeutic empathy. J Clin Psychol 1991;47:444-8.

36 Wündrich M, Schwartz C, Feige B, et al. Empathy training in medical students - a randomized controlled trial. Med Teach 2017;39:1096-8.

37 Bryan CS. "Aequanimitas" redux: william osler on detached concern versus humanistic empathy. Perspect Biol Med 2006;49:384-92.

38 Neumann M, Bensing J, Mercer S, et al. Analyzing the "nature" and "specific effectiveness" of clinical empathy: a theoretical overview and contribution towards a theory-based research agenda. Patient Educ Couns 2009;74:339-46.

39 Coulehan JL, Platt FW, Egener B, et al. "Let me see if i have this right...": words that help build empathy. Ann Intern Med 2001;135:221-7.

40 Kucirka B, Vallone D. Social empathy: Pathway to developing change agents and social justice advocates.

41 Miller C, Saxton J. Developing the capacity for empathy. Drama. 10. Theatre and Performance Education in Canada: Classroom and Community Contexts, 2015.

42 Lorié Áine, Reinero DA, Phillips M, et al. Culture and nonverbal expressions of empathy in clinical settings: a systematic review. Patient Educ Couns 2017;100:411-24.

43 Dyche L, Zayas LH. Cross-cultural empathy and training the contemporary psychotherapist. Clin Soc Work J 2001;29:245-58.

44 DeAngelis T. In search of cultural competence. Monitor on Psychology 2015;46 http://www.apa.org/monitor/2015/03/culturalcompetence

45 Grimm P. Social desirability bias. Wiley international encyclopedia of marketing, 2010. 